\title{
Pathological changes in temporal arteries removed from unselected cadavers
}

\author{
R. W. AinsWorth, G. A. GREShAM, AND G. V. BALMFORTH
}

From the Department of Pathology and Addenbrooke's Hospital, Cambridge

SYNOPSIS Progressive degenerative changes in ageing temporal arteries are described. These changes are usually severe in elderly patients, hence their presence in diagnostic biopsies provides no evidence of temporal arteritis past or present.

In two patients in the series of random necropsies examined there were changes in the temporal arteries identical with those seen in patients known to have suffered from temporal arteritis in the past; in both these cases there was, in addition a giant cell aortitis.

The distinction between healed arteritis and degenerative changes due to age in a single biopsy specimen may be difficult. Furthermore, it is possible that steroid treatment may arrest the progress of the disease so that gross intimal thickening and vascularization of the artery wall do not occur.

Giant cell arteritis is not a rare disease. Two examples were discovered in 39 random necropsies on patients over 60 years of age.

During the examination of temporal artery biopsies it was noticed that those from patients with clinically typical temporal arteritis almost invariably showed active giant cell arteritis, but that there was rarely any histological evidence of active arteritis if the clinical diagnosis was in doubt. However, arteries from patients in this latter group usually showed 'degenerative' changes, frequently so severe as to raise the possibility of damage due to a previous attack of arteritis.

Temporal arteritis is a disease of the elderly, hence artery biopsies from possible cases might be expected to exhibit changes due to age. In order to assess the significance of such changes in biopsies and to distinguish them, if possible, from true healed temporal arteritis the temporal arteries from 60 cadavers were examined; these included both hospital and coroners' cases. The main arteries and a few centimetres of their anterior and posterior branches were removed. Three blocks were prepared from each artery so as to include the main stem and its major branches together with smaller branches if possible. Sections were stained with Ehrlich's haematoxylin and eosin and with Weigert's elastin stain. The series was divided into three age groups. The findings in each group are described below.

Received for publication 3 September 1960.

\section{RESULTS}

YOUNG ADULTS (SEVEN PATIENTS AGED BETWEEN 24 AND 36 YEARS) Some of the medium-sized arteries (main stem and large branches) in every case showed a minor degree of intimal thickening. There was either duplication of the internal elastic lamina and an increase in collagen together with some smooth muscle in the intima (Fig. 1), or thickening by numerous thin elastic laminae, collagen fibres, and some smooth muscle cells. Thickening of the latter type was often distributed in plaques which were frequently conspicuous adjacent to the orifices of small branches, i.e., points where atherosclerosis is common (Fig. 2). The internal elastic lamina was usually intact; if there were breaks they tended to occur next to a plaque of intimal thickening. A new elastic lamina was often developed adjacent to the endothelium overlying such plaques.

40-60 AGE GROUP (14 PATIENTS) Intimal thickening of the same types was more conspicuous and affected both large and small arteries. In seven patients there was evidence at necropsy of hypertensive cardiovascular disease, but the intimal thickening was not significantly greater in these. In a few arteries small atherosclerotic plaques were present. These were formed by rather granular elastic fibres interlaced with collagen fibres and contained some foamy 115 


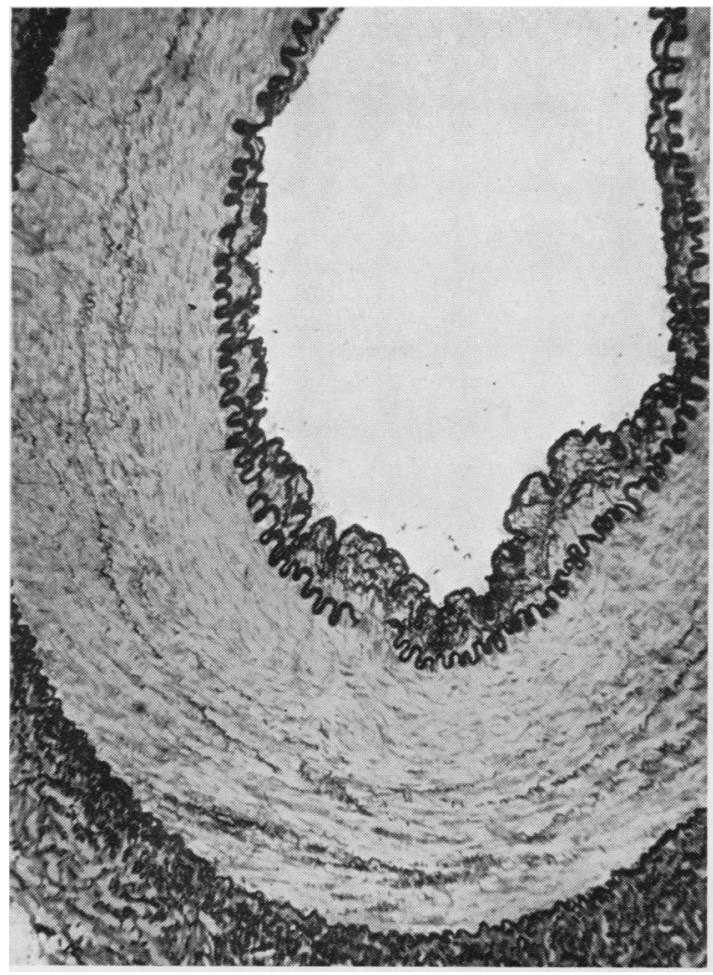

FIG. 1

FIG. 1. Temporal artery from a male aged 24 years (Weigert's elastin stain $\times 85$ ).

FIG. 2. Plaques of intimal thickening (T) adjacent to the orifice of a small branch $(V)$ (Weigert's elastin stain $\times 140$ ).

FIG. 3. An atheromatous plaque $(P)$ in a temporal artery (Weigert's elastin stain $\times 110)$.

FIG. 3
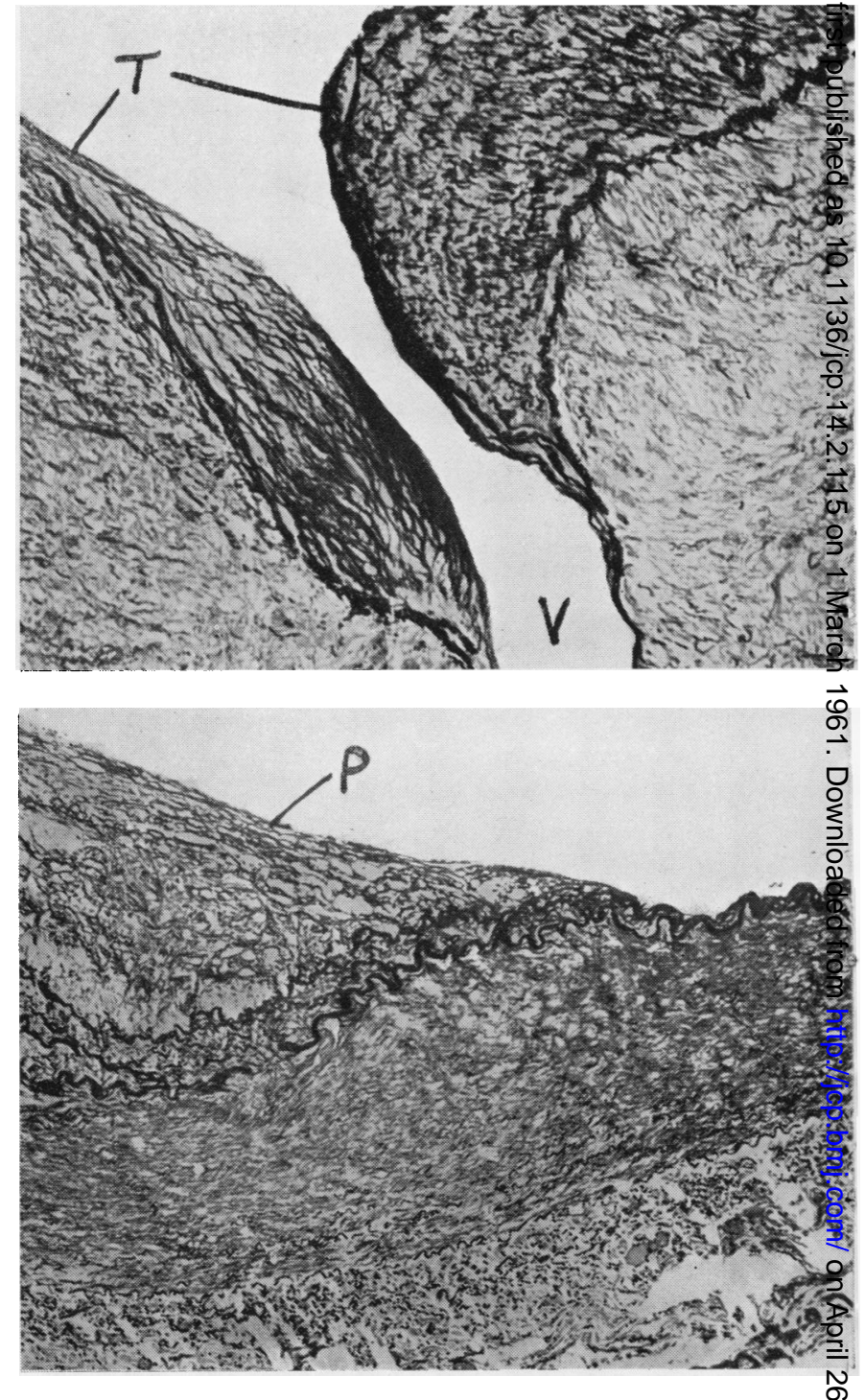

macrophages (Fig. 3). 'Stretching' and fragmentation of the internal elastic lamina was often present beneath these plaques. The media was usually well defined and composed of circular muscle, except beneath some of the intimal plaques where the muscle fibres sometimes appeared to be longitudinal and continuous with smooth muscle in the intima through breaks in the internal elastic lamina.

Lesser degrees of the degenerative changes in the internal elastic lamina and of the associated fibrosis seen in the over- 60 group were found in some of the arteries in this group.

OVER-60 GROUP (39 PATIENTS) Thirteen patients in this group were aged 80 or more years. The intimal thickening tended to be more marked, though not in every case, and its degree was not related to hypertension. It usually consisted of

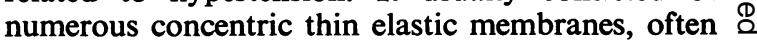
showing considerable fragmentation together with 


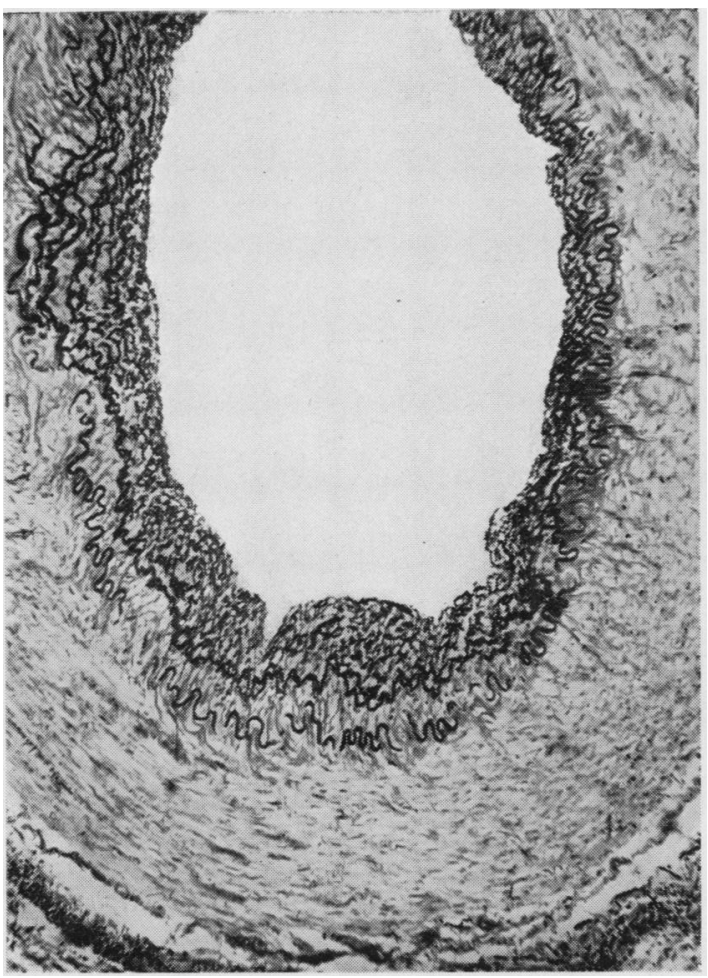

FIG. 4a. Temporal artery from a female aged 79 years (Weigert's elastin stain $\times 85$ ).

some collagen and smooth muscle. Degenerative changes in the internal elastic lamina were the most important feature of this group, and were present to some extent in every patient. These changes included fragmentation, partial loss, and a change in staining properties (Figs. 4a, 4b). Often the internal elastic lamina was more eosinophilic than normal and had lost much of its black-staining properties with Weigert's elastin stain, appearing as a rather swollen, often fragmented, greenish-yellow refractile membrane. This last change was very common in patients over 80 years of age. In two patients patchy calcification of the degenerating membrane was observed. A variable degree of fibrosis occurred in relation to the degenerating membrane and was seen as dense, often hyaline, collagen which extended into the media and adjacent intima. Sometimes these collagen fibres appeared to have a radial arrangement and were associated with longitudinal smooth muscle. The media might show generalized loss of muscle with replacement fibrosis, and in a few arteries medial calcification was present. Inflammatory cellular infiltration (mainly lympho-

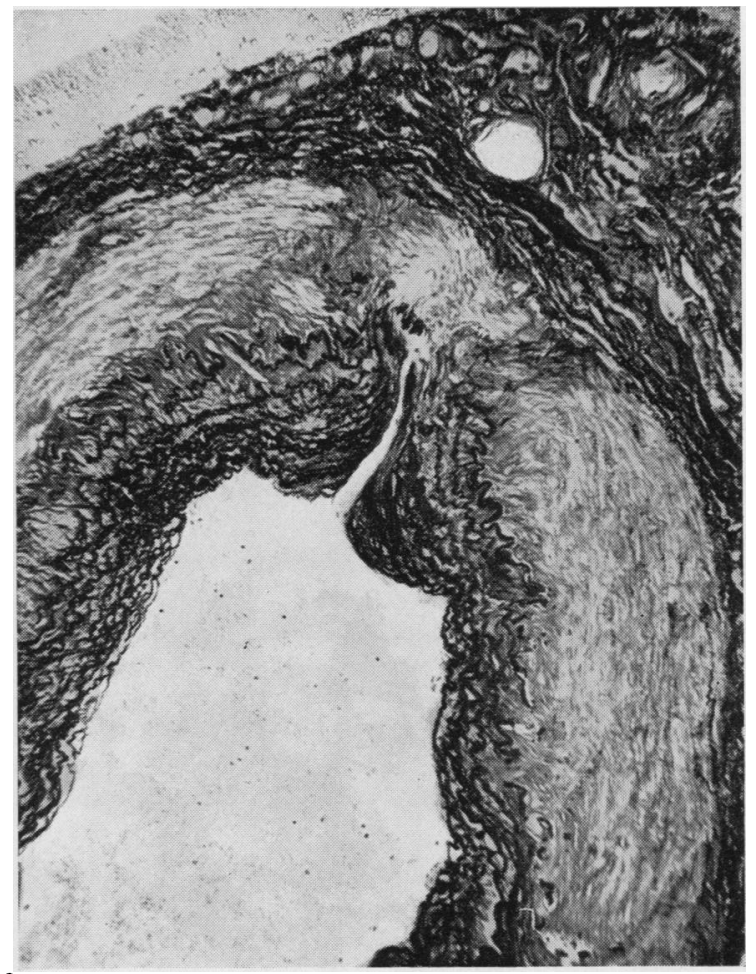

FIG. 4b. Temporal artery from a male aged 67 years. Note fibrosis in relation to the degenerating internal elastic lamina (Weigert's elastin stain $\times 85$ ).

cytes in the adventitia) and vascularization of the walls of senile arteries (except in the two patients cited below) only occurred in relation to large atherosclerotic plaques; these were uncommon, being present in only one pair of arteries.

In two patients, aged 85 and 86 years, the histological appearances of the temporal arteries (both large and small branches) differed from those in the arteries of the corresponding age group. The changes were bilateral and comprised extensive loss of the internal elastic lamina, elastin preparations showing a few black granular fragments or a layer of diffuse granular material in its place; blood vessels, mainly capillaries, with conspicuous endothelial cells and some arterioles in the outer intima and inner media; considerable intimal thickening by concentric collagen fibres, rather granular elastic fibres, and numerous smooth muscle cells, the smooth muscle frequently forming a well-developed circular layer adjacent to the narrowed lumen; a new elastic lamina just beneath the endothelium; moderate fibrosis in the media usually in relation to the damaged internal elastic lamina; fibrous thickening and increased 


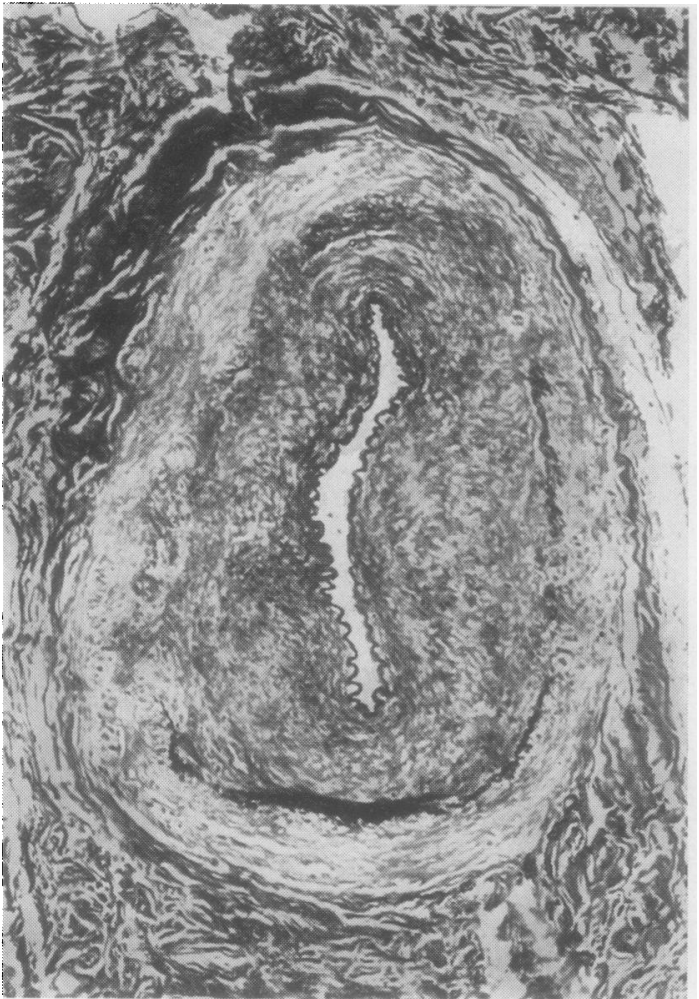

FIG. 5a. Healed arteritis. Temporal artery from patient with aortic aneurysm (Weigert's elastin stain $\times 110)$.

vascularity of the adventitia, with fragmentation and loss of the external elastic lamina (Fig. 5a, 5b). These changes were thought to provide evidence of healed arteritis. Reference to the necropsy findings revealed that the first patient died from myocardial infarction and histological examination showed an active giant cell aortitis and healing arteritis in small branches of the coronary arteries. The second patient had ruptured a fusiform aneurysm of the descending thoracic aorta. In sections of the aorta there was evidence of a late stage of giant cell aortitis and the anterior descending branch of the left coronary artery showed healing giant cell arteritis. The aorta was examined histologically in 29 other patients in this series; in none was there any evidence of giant cell aortitis.

\section{DISCUSSION}

The clinical and pathological features of temporal (giant cell) arteritis were first described by Horton, Magath, and Brown (1932, 1934) and numerous examples have since been reported (Roux, 1954). It

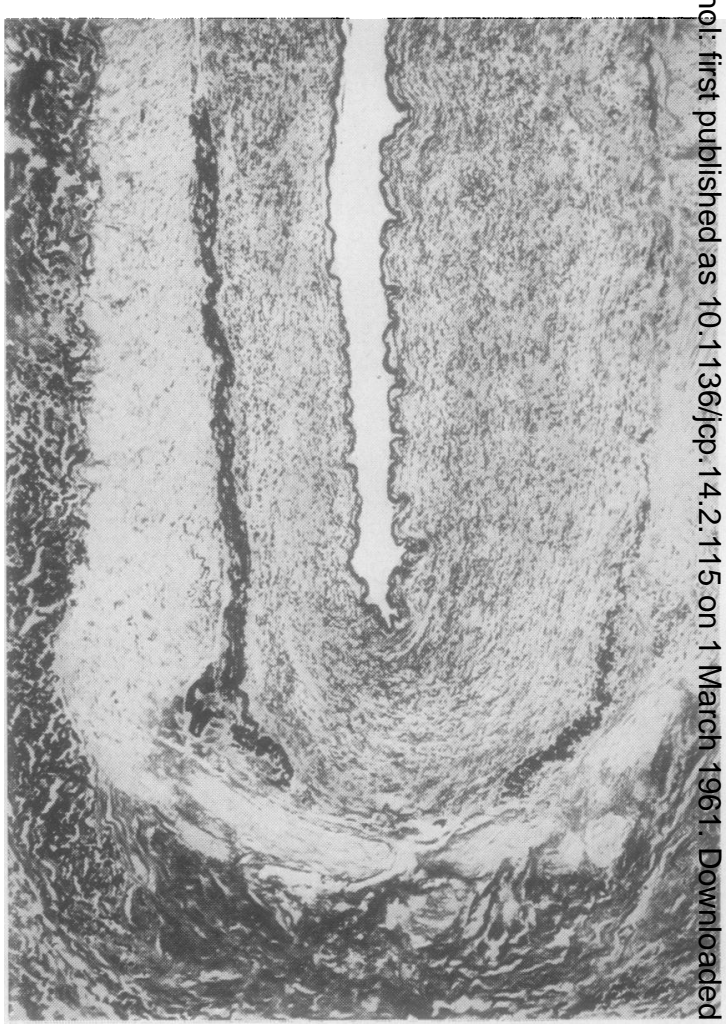

FIG. 5b. Main stem of temporal artery from same patie $\overrightarrow{\bar{A}} t$ as in Fig. 5 a (Weigert's elastin stain $\times 100)$.

is now recognized that the disease is not as rare $\overline{8}$ was formerly believed (Robertson, 1952; Camerow, 1959).

The histopathological features of the active phase have been frequently described (Cooke, Cloak, Govan, and Colbeck, 1946; Harrison, 1948; Cardell and Hanley, 1951; Kimmelstiel, Gilmour, and Hodges, 1952; Lander and Bonnin, 1956), but mue less attention has been paid to the appearances $\overline{\bar{\rho} f}$ healed arteritis and how these may be distinguished from degenerative changes commonly present in the temporal arteries of elderly patients. Kimmelstiel ¿tt al. (1952) compared the 'senile' changes in tbe temporal arteries of 50 elderly persons with the changes seen in temporal arteritis. At no time we fe senile degenerative changes associated with a giafat cell reaction, a finding confirmed by the present results. They noted hyaline connective tissue $\overline{\text { qn }}$ relation to the internal elastic lamina of senge arteries, a change they called "perielastic hyalinosi $\overrightarrow{8}$ ".

Inflammatory cellular infiltration of the artesy wall was not seen in senile arteries, except occasionally in relation to large atherosclerotic plaques. of 


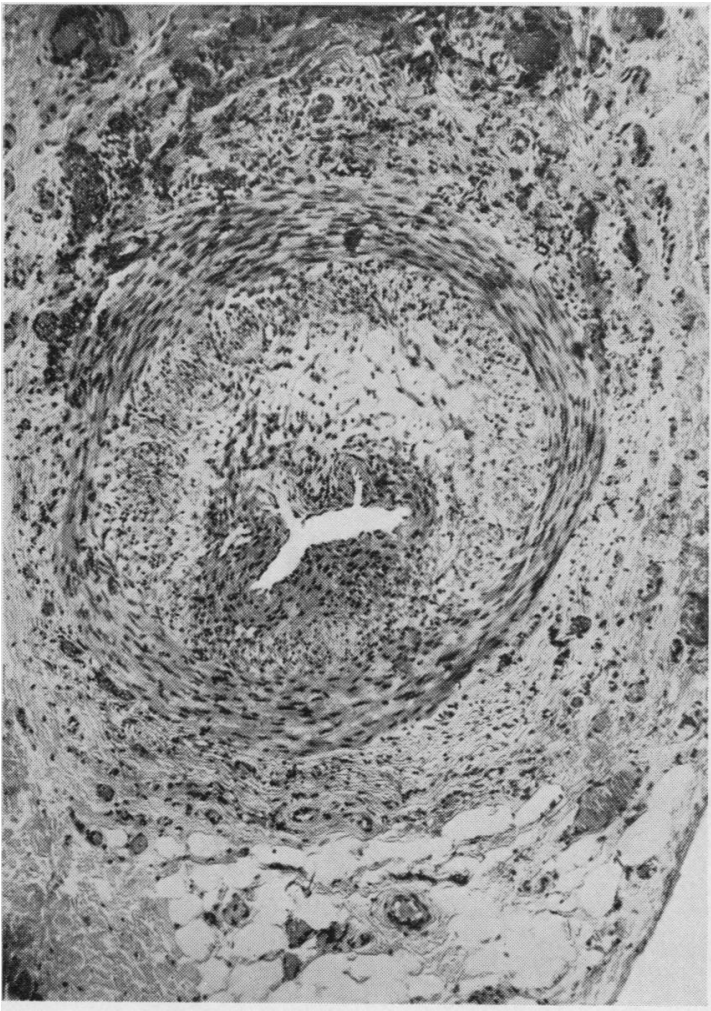

FIG. 6a. Temporal artery biopsy from patient with history of temporal arteritis two years previously (haematoxylin and eosin $\times 85$ ).

study of biopsies from 22 typical clinical examples of temporal arteritis has shown that inflammatory cellular infiltration often persists until a late stage in the healing process. Even when inflammatory cells have completely disappeared an artery damaged by giant cell arteritis is likely to show certain histological features which differ from those present in 'senile' arteries, viz., greater intimal thickening, often with a well-developed layer of smooth muscle adjacent to the lumen, vascularization of the artery wall, and considerable loss of the internal elastic lamina, surviving segments often appearing as a granular black layer in elastin preparations.

However, the distinction between healed arteritis and degenerative changes due to age in a single biopsy specimen may be difficult. Difficulty may also be experienced in studying patients suffering from giant cell arteritis who have received steroid treatment before biopsy is performed. Steroids are thought to reduce the oedema and inflammatory cellular reaction in giant cell arteritis (Harrison, Harrison, and Kopelman, 1955), and should this

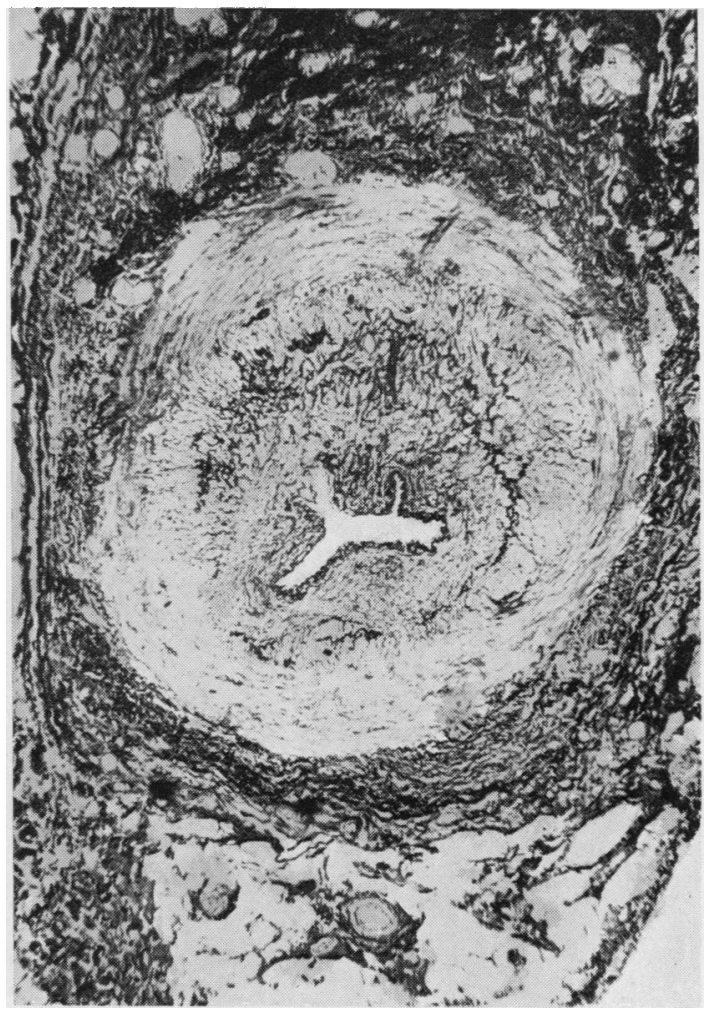

FIG. 6b. Same as Fig. $6 a$ (Weigert's elastin stain $\times 85$ ).

occur before gross intimal thickening and vascularization of the wall takes place, it is possible that the residual changes might be indistinguishable from those due to senile degeneration.

We are grateful to Dr. A. M. Barrett and to H.M. Coroners of the City and County of Cambridge for permission to use the material. Mr. S. W. Patman prepared the photomicrographs.

\section{REFERENCES}

Cameron, A. (1959). Brit. med. J., 2, 1291.

Cardell, B. S., and Hanley, T. (1951). J. Path. Bact., 63, 587.

Cooke, W. T., Cloake, P. C. P., Govan, A. D. T., and Colbeck, J. C. (1946). Quart. J. Med., New Series, Vol 15, 39, 47.

Harrison, C. V. (1948). J. clin. Path., 1, 197.

Harrison, R. J., Harrison, C. V., and Kopelman, H. (1955). Brit. med. J., 2, 1593.

Horton, B. T., Magath, T. B., and Brown, G. E. (1932). Proc. Mayo Clin., 7, 700.

(1934). Arch intern. Med 53, 400.

Kimmelstiel, P., Gilmour, M. T., and Hodges, H. H. (1952). A.M.A. Arch. Path., 54, 157.

Lander, H., and Bonnin, J. M. (1956). J. Path. Bact., 71, 369.

Robertson, K. M. (1952). Proc. roy. Soc. Med., 45, 500.

Roux, J. L. (1954). Helv. med. Acta (Basel), 21, Suppl. 34. 